Bulletin de la Société Royale des Sciences de Liège, Vol. 86, special issue, 2017, p. 1 - 6

\title{
The effect of ozone gas on destruction and detoxification of aflatoxin
}

\author{
Shohreh MALlaKian $^{1}$, Roghayeh ReZaneZHAD ${ }^{2}$, Mahdi JALALI ${ }^{* 3}$, Fatemeh GHOBAdi $^{4}$ \\ ${ }^{1}$ MSc. Student, Department of Food Science and Technology, Sabzevar Branch, Islamic Azad \\ University, Sabzevar, Iran \\ ${ }^{2}$ MSc. Student, Department of Food Science and Technology, Quchan Branch, Islamic Azad \\ University, Quchan, Iran \\ ${ }^{3}$ University of Applied Science and Technology, Khorasan Razavi, Iran \\ ${ }^{4}$ BS. Student, University of Torbat-e-Jam, Khorasan Razavi, Iran
}

\begin{abstract}
Aflatoxins are more significant than other fungal toxins due to carcinogenic effects and acute poisoning. In nature, four types of aflatoxin including $B_{1}, B_{2}, G_{1}$ and $G_{2}$ and also two types of metabolic products named $\mathrm{M}_{1}$ and $\mathrm{M}_{2}$ are found. These components can pollute livestock and human feeds like corn, sorghum, wheat, soya, cottonseed, peanut and nuts. To control aflatoxin, physical separation, deactivation by heat and microbes, radiography, solvent extraction and fermentation are used. Ozone is one of the eliminating compounds of aflatoxin that has capability tocarry out the process in three status of dry, watery and moist. Ozone can eliminate fungal toxins through reacting with 8 and 9 dual bond of furan ring in aflatoxin which means initial ozonation and subsequently rearrangement to derivations and then producing aldehydes, ketones and organic acids.
\end{abstract}

Keywords: Aflatoxin, Ozone, Deactivation methods

\section{Introduction}

Aflatoxins are toxins which are produced by some of fungus growing on livestock feed and foods and can cause aflatoxicosis disease in human and domestic animals. Different environmental factors are involved in producing aflatoxin. So, the severity of pollution depends on geographic location, agricultural technique, products' sensitivity before harvesting, process of foods' production and statusof products in the store. Aflatoxins are more important than other fungal toxins because of carcinogenic effects and acute poisoning [1].

Aflatoxins are a sort of mycotoxins which created by two types of molds named Aspergilus Flavous and Aspergilus Parasiticus. Based on studies, in nature, four types of aflatoxin including $B_{1}, B_{2}, G_{1}$ and $\mathrm{G}_{2}$ and two kinds of metabolic products such as $\mathrm{M}_{1}$ and $\mathrm{M}_{2}$ are available that can pollute livestock and human feeds like corn, sorghum, wheat, soya, cottonseed, peanut and nuts.

Aflatoxin $\mathrm{B}_{1}$, with molecular weight of 312 and $\mathrm{C}_{17} \mathrm{H}_{12} \mathrm{O}_{2}$ formula, shows a relatively strong blue fluorescence against UV. $\mathrm{B}_{1}$ consists of colorless crystals that hydrolyzed at the melting point of $268^{\circ} \mathrm{C}-269^{\circ} \mathrm{C} . \mathrm{G}_{1}$, with 328 molecular weight and $\mathrm{C}_{17} \mathrm{H}_{12} \mathrm{O}_{7}$ formula, shows green fluorescence against UV and its melting point is $244^{\circ}{ }^{\circ}-246^{\circ} \mathrm{C}$.

$\mathrm{B}_{2}$ and $\mathrm{G}_{2}$ are available in nature with 314 and 330 molecular weight and $\mathrm{C}_{17} \mathrm{H}_{14} \mathrm{O}_{6}$ and $\mathrm{C}_{17} \mathrm{H}_{14} \mathrm{O}_{7}$ formula, respectively. Also, these aflatoxins stream blue and green fluorescence against UV and

\footnotetext{
1. Superior Expert, Khorasan Razavi Province, General Office of Standard

*Corresponding author email: mehdijalali62@yahoo.com
} 
their melting point is $268^{\circ} \mathrm{C}-289^{\circ} \mathrm{C}$ and $240^{\circ} \mathrm{C}-247^{\circ} \mathrm{C}$, respectively. $\mathrm{B}_{2}$ and $\mathrm{G}_{2}$ could be taken by careful hydrogenation of $B_{1}$ and $G_{1}$. If $B_{1}$ is eaten singly by animals or with other aflatoxins in livestock feed, it's converted to other aflatoxins in animals' tissues and secretions. $\mathbf{M}_{1}$ and $\mathrm{M}_{2}$ are considered as milk toxins and found in animals' milk. $\mathrm{M}_{1}$ and $\mathrm{M}_{2}$ are structurally derivations of 4hydroxy aflatoxin $B_{1}$ and $B_{2}$. After being eaten $B_{1}$ by animal or after being injected directly to animal, 4-hydroxy aflatoxin is detectable in urea, stool, muscles, liver and kidney.

$\mathrm{M}_{1}$ can tolerate the temperature of pasteurization. Conducted studies have proved the resistance of $\mathrm{M}_{1}$ for milks which had been polluted naturally or artificially. This toxin endures the temperature of $64^{\circ} \mathrm{C}$ for two hours and can keep the own initial shape but its structural stability is reduced with increasing temperature. These aflatoxins are solid crystals and $\mathrm{M}_{1}$ and $\mathrm{M}_{2}$ have the melting point of $299^{\circ} \mathrm{C}$ and $293^{\circ} \mathrm{C}$, respectively.

These toxins are found in milk, cheese, peanut, cottonseed, almond, condiments and fig and in various types of livestock and human feeds and also could be measured. Sometimes becauseof using polluted feed, egg and meat products are polluted by aflatoxin [2].

Some factors such as pollution of agricultural products before harvesting, putting the drying time of products off and high percentage of products' moisture, existing pests in vegetable and storehouse and also food storage conditions in the storehouse (for temperature and moisture) can create required field to grow fungus and produce aflatoxin. Moreover, other agents like stress caused by lack of water and drought, poor fertility of plants and their high aggregation in the farm, existence of weeds and increasing environment temperature play a role in proliferating molds and producing toxin [3].

If human daily receives aflatoxin $\mathrm{B}_{1}$ less than 10 micrograms per $\mathrm{kg}$ of body weight for a long-term, he/she suffers from temporary effects. But if the amount of $\mathrm{B}_{1}$ reaches to 50 micrograms, important epidemiologic and clinical effects will happen. Meanwhile, it could be said that augmentation of malnutrition about calorie and protein followed by $B_{1}$ and immune system suppression even occurred due to infection. People who expose to risk factors such as hepatitis, cirrhosis of the liver, aflatoxins, senility and hereditary factors, it is more likely to suffer from liver cancer [4]. Various factors are involved in making decision for regulating of aflatoxins' restriction including availability of toxins in aflatoxins, awareness of distribution of aflatoxin concentration in a large number of products, supervision laws and necessity amount of foods [5].

Physical separation, deactivation by heat and microbes, radiography, solvent extraction and fermentation are utilized to control aflatoxin. Among these methods, chemical methods are applied as a main strategy for neutralization. Recent researches show that existing nutrients like proteins, fats, vitamins, rare ingredients, additives such as antibiotics and preservatives cause decrease of poisonous effects of aflatoxin. So, new methods are studied to neutralize aflatoxin's effects in which inorganic absorbents (or chemical absorbents) are added to animal feed. One of these absorbents is HSCAS (Hydrated Sodium Calcium AluminoSilicate). HSCAS makes a conjunction with aflatoxin's molecules and causes this toxin becomes static. Thereby, HSCAS prevent absorption of these molecules by body [6] and [7].

\section{Deactivation methods of aflatoxins}

\subsection{Physical methods}

Aflatoxins' sensitivity against heat depends on environmental condition. Moisture in foods causes increase of decomposition percentage and elimination of aflatoxins. This action is performed through hydrolysis of lactone ring in effective moisture concentrations and temperature. Presence of proteins and other food components in the environment cause maintenance and consistence of aflatoxins in heated foods. So, heat penetration is decreased and aflatoxins are stabilized. 
Nowadays, $100 \%$ of aflatoxin in edible oils is eliminated helping filters and filtration in different industries especially in oil industry. Centrifuge is able to eliminate $65 \%$ of aflatoxins in peanut oil and the rest of it (35\%) can be removed by active soils and adsorption of aflatoxin.

Ionizing radiations like Gamma are mostly used to remove pathogenic microorganisms from different foods and any types of livestock feed. Gamma has more impact compared to visible radiation or UV because of its high penetration into solids and liquids than other radiations. But organic molecules with complex structure like aflatoxins are resistant against Gamma and indirect impact of Gamma causes decomposition of aflatoxins so that it can decompose water and results in releasing radicals and consequently required condition is made to destroy and decompose aflatoxins.

\subsection{Chemical methods}

Sodium chlorite is applied to eliminate aflatoxins from polluted surfaces as the main chemical substance. Foods' chlorination with sodium hypochlorite in $0.2,1,5$ and $11 \%$ concentrations and hydrochloric acid $3 \%$ or gas $10 \%$ leads to decomposition of B1 in foods. The minimal concentration of sodium hypochlorite to decompose aflatoxin in foods completely is $8.8 \times 10^{-3}$ mole in a two hours period. Controlling environment $\mathrm{pH}$ plays an effective role for better impact of sodium hypochlorite and Clare works as a dominant oxidizing under acidic conditions.

It should be noted that foods' chlorination has problems about removing aflatoxins from the aspect of safety and health of foods, because Clare in residual foods and in fats and proteins reshapes and eventually produces toxins. Hydrogen peroxide is a cheap substance that is available easily and has a high efficiency in decomposing fungal toxins. Also, it prevents the growth of fungus producing aflatoxin in artificial cultures and decomposes toxins completely in $0.5 \%$ concentration and $\mathrm{pH}=4$ and/or $6 \%$ concentration and $\mathrm{pH}=9.5$.

Sodium bisulfite has utilization in food industries as an additive. It's used in destruction of fungal toxins and causes deactivation of poisons in 0.5 and $1 \%$ concentration. $95 \%$ of aflatoxinsin livestock feed are decomposed by liquid or gas ammonia. If some factors like time, temperature and concentration are utilized properly, it has highly deconstructive impact. For example, food is needed to be heated 15-30 minutes in $80^{\circ} \mathrm{C}-120^{\circ} \mathrm{C}$ temperature and high pressure. Ammonia decreases toxicity with decarboxylation and hydrolysis of ketone ring of $B_{1}$ and converts it to $D_{1}$ [7] and [8].

\subsection{Biological and microbial methods}

HSCAS, is an acceptable absorbent that protects farm animals against aflatoxicosis. But it's not effective against other mycotoxins such as fumonisin, deoxynivalenol (DON) and ochratoxin A. So, organic components connect to mycotoxins using special chemical methods. These converted absorbents called organoclays. Microbial or enzymatic detoxification is another method to detoxify aflatoxins. This method is decomposition or structural deformation which leads to make nontoxic or less toxic products. In 1966, it was cleared that microorganisms such asyeasts, molds, molds' spore, actinomycetes, bacteria, mosses and algae can be used to remove mycotoxins. Flavobacteriumaurantiacum (B-184NRRJ) can cause the destruction of aflatoxin in culture and its detoxification has been proved in milk, oil, corn, peanut butter, bran and almond [9] to [13].

As a part of deactivation method was explained for aflatoxins, the use of ozone as an oxidant could be mentioned.

In nature, ozone is found in two forms. In stratosphere (about 10-15 km above planet) and in the earth, it exists as an earth protective layer against UV. The color of ozone is blue. Ozone consists of three atoms of oxygen and is found in nature cycle. It has high deoxidization ability. Ozone easily reacts with other molecules and changes their molecular structure. It's very unstable and if it doesn't face with molecules withoxidation ability, it reshapes again and is converted to oxygen [14] and [15]. 
Table 1. Ozone characteristics

\begin{tabular}{ll}
\hline \multicolumn{1}{c}{ Chemical name } & \multicolumn{1}{c}{ Ozone } \\
\hline & \\
Shape & Colorless and sharp smell \\
Molecular formula & $\mathrm{O}_{3}$ \\
Registration $\mathrm{N}^{\circ}$. & $10025-15-6$ \\
Molecular weight & $48.0 \mathrm{~g} / \mathrm{mol}$ \\
Concentration (gas) & $2.144 \mathrm{~kg} / \mathrm{m}^{3}$ \\
Liquid (NTP) & $1574 \mathrm{~kg} / \mathrm{m}^{3}$ \\
Solid & $1728 \mathrm{~kg} / \mathrm{m}^{3}\left(-183^{\circ} \mathrm{C}\right)$ \\
Solving in water & $4.9 \mathrm{ml} / 1\left(0^{\circ} \mathrm{C}\right)$ \\
Boiling point & $-111.9^{\circ} \mathrm{C}(1 \mathrm{~atm})$ \\
Melting point & $-192.5^{\circ} \mathrm{C}(1 \mathrm{~atm})$ \\
\hline
\end{tabular}

Ozone passes $50 \%$ faster than Clare from cellular membrane and eliminates a various number of bacteria 3000 times faster than Clare. Even in low concentration, it has high disinfection power and doesn't produce any byproduct when converting to oxygen [16].

Ozone can react with 8 and 9 dual bond of furan ring in aflatoxin. It means that it causes destruction by initial ozonation and rearrangement to derivations (monozonide) and production of aldehydes, ketones and organic acids. To do this action, three methods are available including drying, watery and moist process.

In drying method, ozone enters into the glass reactor directly and after putting sample into the reactor, oxygen cylinder faucet and flow are opened quickly. So, oxygen and ozone are injected to the reactor from the bottom and upper side of generator, respectively. Watery process is the second method in which water is added and sample becomes float. During enrichment, vapor ozone is used directly to be entered into the water and some reactions occur between watery ozone and aflatoxin. In moist process, there is a water container between generator and reactor of ozone. Vapor ozone which was produced in the first step enters into the water and then sample is injected to the ozone reactor. In the following, the reaction between vapor ozone and aflatoxin is performed.

The destructive effect of ozone is done by these three methods. Moist process has highest destructive effect and lowest impact is related to drying method. In watery process, ozone is widely used in food industries (i.e. for stored grains). But it's not suitable for storage media. It seems that water or steam has a main role in reacting between ozone and aflatoxin.

$$
\begin{aligned}
& \mathrm{O}_{3}+\mathrm{H}_{2} \mathrm{O} \rightarrow \mathrm{H}_{3} \mathrm{O}^{+}+\mathrm{OH}^{-} \\
& \mathrm{H}_{3} \mathrm{O}+\mathrm{OH}^{-} \rightarrow 2 \mathrm{H}_{2} \mathrm{O} \\
& \mathrm{O}_{3}+\mathrm{H}_{2} \mathrm{O}^{-} \rightarrow \mathrm{OH}^{-}+2 \mathrm{O}_{2} \\
& \mathrm{HO}+\mathrm{H}_{2} \mathrm{O}^{+} \rightarrow \mathrm{H}_{2} \mathrm{O}+\mathrm{O}_{2}
\end{aligned}
$$

In this reaction, free radicals like $(\mathrm{OH})$ show the ability of powerful oxidation of ozone. So, the oxidation ability of ozone has been greatly increased from evaporated water. In conducted studies about destroying aflatoxinsby ozone, it was concluded that ozone follows of creegie mechanism using electrochemical oxidation of water in medium acidic environment so that it initiates a reaction by attacking to $\mathrm{C} 8-\mathrm{C} 9$ band in aflatoxin and after initial formation (ozonide) and rearrangement (molozonide), it's converted to types of carbonyl components such as aldehydes, ketones and organic acids. Finally, reaction is directed toward byproducts including $\mathrm{CO}_{2}$ and $\mathrm{H}_{2} \mathrm{O}$. One way to deactivate aflatoxin by ozone is reacting ozone with initial shape of $\mathrm{N}$-oxide amine in aflatoxin and with losing second hydrogen of third carbon $\left(\mathrm{C}_{3}\right)$, it can produce ketone including 3-keto [14], [17] and [18]. 
Ozone was used for date fruit with 1, 3 and 5 ppm concentrations in 15, 30, 45 and 60 minutes and a significant decrease was observed in Staphylococcus aureus and E. coli [19]. Ozone even decreased the amount of polyphenols and oxidative products in peanut's skin. This action was performed by HPLC and MS devices [20]. To decrease microbial charge and eliminate Salmonella, Listeria monocytogenes and E. coli from edible fungi, 2.8 and $5.3 \mathrm{mg} / \mathrm{l}$ ozone concentrations were used for 60 minutes and the amount of bacteria declined 3.61, 2.8 and 3.41 logarithmic phase [21].

Spore (Penicillium expansum) is eliminated due to continuous contact with ozone, while its colony is very resistant on packing surface and isn't eliminated because of continuous contact with the air containing ozone $0.72 \mathrm{ppm}$ for five months [22]. The inhibitory effect of ozone has been determined on decay of orange, strawberry and peach because of Penicillium, Botrytis cinerea and Monilinia fruticola, respectively [23].

Now, green mold's spore has become resistant to fungicides. Thereby, ozone is utilized for slowing spore production in injured fruits. So, decay is prevented during packing. Controlling ozone's sporulation has been observed in citrus which are kept in cold storehouse in $50^{\circ} \mathrm{F}$ temperature and/or less. Controlling sporulation was seen in $0.06 \mathrm{ppm}$ ozone concentration. However, its penetration with $0.01 \mathrm{ppm}$ concentration or less doesn't lead to control sporulation in oranges inside the plastic packs or fibrous boxes [24].

In conducted study on fig containing $B_{1}$, two types of ozone (gas and liquid) were used and the results showed that the destruction of toxin is raised with increasing exposing time in ozone condition [25]. In a study about the destruction of aflatoxin in pistachio, 5,7 and $9 \mathrm{mg} / \mathrm{l}$ ozone concentrations were used in the temperature of $20^{\circ} \mathrm{C}$ and $70 \%$ relative humidity for 140 and 240 minutes and eventually liquid chromatography with high efficiency was applied for evaluating [26].

\section{CONCLUSION}

In conducted studies, ozone has a high oxidative power (50 times stronger than Clare) and also has impact on various spectrums of microorganisms including fungus that are main producer of mycotoxins especially aflatoxins. Destructive effect of ozone is performed by three methods that moist process has highest destructive impact and drying process has lowest effect. Watery ozone is widely used in food industries including stored grains but it's not suitable for storage environment.

\section{References}

[1] Eaton, D.L., Groopman, J.D. (1994). The Toxicology of Aflatoxins. Academic Press, New York, p. 383-426.

[2] Özsoy, S., Altunatmaz, K., Horoz, H., Kasikci,G., Alkan, S., Bilal, T. (2005). The relationship beetwen lameness, Fertility and aflatoxin in a dairy cattle herd. Turkish Journal of Veterinary and Animal, vol. 29, p. 981-986.

[3] Clements, M.J., White, D.G. (2004). Identifying sources of resistance to aflatoxin and fumonisin contamination in corn grain. Journal of Toxicology, vol. 23, no. (2,3), p. 381-396.

[4] Bryden, W.L. (2007). Mycotoxins in the food chain:human health implications. Journal of Clinical Nutrition, vol. 16, p. 95-101.

[5] Yiannikouris, A., Jouany, J.P. (2002). Mycotoxins in feeds and their fate in animals: a review. Animal Research, vol. 51, p. 81-99.

[6] Morgavi, D.P., Riley R.T. (2007). An historical overview of field disease outbreaks known or suspected to be caused by consumption of feeds contaminated with Fusarium toxins. Animal Feed Science and Technology, vol. 137, p. 201-212.

[7] Milicevic, D.R., Skrinjar, M., Baltic, T. (2010). Real and perceived risks for mycotoxin contamination in foods and feeds: Challenges for food safety control. Journal of Toxins, vol. 2, p. 572-592. 
[8] Carlson, M.P., Ensley, S.M., Grant, R.J., Smith, D.R. (2002). Aflatoxin M1 in milk. University of Lincoln.

[9] Orr, D. (2002). Aflatoxin Hand Book (Chapter.1). U.S.Department of agriculture grain in section. Packers and stockyards administration federal grain inspection service, Stop 3630, Washington, DC. 20090-3630

[10] Turyk, M.E., Persky, V.W., Imm, P., Knobeloch, L., Chatterton, R., Anderson, H.A. (2008). Aflatoxin M.1 in milk and dairy products. Plos One, vol. 10, p. 31-34.

[11] Baker,T., Herrman,T.J., Loughin,T. (2010). Quality management for feed related disease prevention. Kansas State University Manhattan.

[12] Safara, M., Zaini, F., Hashemi, S.J., Mahmoudi, M., Khosravi, A., Aliabadi, F. (2010). Aflatoxin detoxification in rice using citric acid. Journal of Public Health, vol. 39, p. 24-29.

[13] Reddy, S.V., Waliyar,F. (2011). Properties of aflatoxin and it producing fungi. International crops research institute for the semi-arid tropics.

[14] Wang, S., Liu, H., Lin, J., Cao, Y. (2010). Can ozone fumigation effectively reduce aflatoxin B1 and other mycotoxins contamination on stored grain?.10th International working conference on stored product protection: Julius-Kühn-Archiv, vol. 425, p. 582-588.

[15] Kenzie, K.S., Sarr, A.B., Mayura, K., Bailey, R.H., Kubena, L.F., Phillips, T.D. (1997). Oxidative degradation and detoxification of mycotoxins using a novel source of ozone. Food and Chemical Toxicology, vol. 35, p. 807-820.

[16] Hoveid, H., Bidhendi, G., Jafari, H.R., Nasrabadi, T. Shahriari,T. (2008). Evaluating the use of ozone for disinfection of drinking Water, case study: Tehran Pars watertreatment plant (Iran). Journal of Environmental Science, vol. 2, p. 31-38.

[17] Mason, L.J., Woloshuk, C.P., Menodoza, F., Maier, D.E., Kells, S.A. (2006). Ozone: A new control strategy for stored grain.9th International working conference on stored product protection: Alternative Methods to Chemical Control, PS7-33, p. 904-907.

[18] Murphy, P.A., Hendrich, S., Landgren, C., Bryany, C.M. (2006). Food mycotoxins: An Update. Journal of Food Science, vol. 71, p. 51-65.

[19] Habibi Najafi, M.B., Haddad Khodaparast, M.H. (2009). Efficacy of ozone to reduce microbial populations in date fruits. Food Contorl, vol. 20, no. 1, p. 27-30.

[20] Diao, E., Shen, X., Zhang, Z., Ji, N., Ma, W., Dong, H. (2014). Indentification of the oxidative products and ozonolysis pathways of polyphenols in peanut skins. Journal of Food and Nutrition Research, vol. 2, no. 3, p. 101-108.

[21] Akata, I., Torlak, E., Erci, F. (2015). Efficacy of gaseous ozone for reducing microflora and foodborne pathogens on button mushroom. Postharvest Biology and Technology, vol.109, p. 40-44.

[22] Palou, L., Smilanick, J.L., Crisosto, C.H., Mansour, M., Plaza, P. (2003). Ozone gas penetration and control of the sporulation of Penicillium digitatum and Penicillium italicum within commercial packages of oranges during cold storage. Crop Protection, vol. 22, p. 1131-1134.

[23] Palou, L., Smilanick, J.L., Crisosto, C.H., Mansour, M. (2001). Effect of gaseous ozone exposure on the development of green and blue molds on cold stored citrus fruit. Plant Disease, vol. 85 , no. 6 , p. 632-638.

[24] Nadas, A., Olmo, M., Garcia, J.M. (2003). Growth of Botrytis cinerea and strawberry quality in ozone-enriched atmospheres. Journal of Food Science, vol. 68, p. 1798-1802.

[25] Zorlugenç, B., Zorlugenç, F.K., Öztekin, S., Evliya, I.B. (2008). The influence of gaseous ozone and ozonated water on microbial flora and degradation of aflatoxin $\mathrm{B}_{1}$ in dried figs. Food and Chemical Toxicology, vol. 46, no. 12, p. 3593-3597.

[26] Akbas, M.Y., Ozdemir, M. (2006). Effect of different ozone treatments on aflatoxin degradation and physicochemical properties of pistachios. Journal of the Science of Food and Agriculture, vol. 86, no. 13, p. 2099-2104. 